\title{
Myeloid/Lymphoid Neoplasms with Eosinophilia and Rearrangement of PDGFRA, PDGFRB, or FGFR1, or with PCM1 - JAK2
}

National Cancer Institute

\section{Source}

National Cancer Institute. Myeloid/Lymphoid Neoplasms with Eosinophilia and

Rearrangement of PDGFRA, PDGFRB, or FGFR1, or with PCM1-JAK2. NCI Thesaurus.

Code $C 84270$.

A group of rare myeloid and lymphoid neoplasms characterized by rearrangement of the PDGFRA, PDGFRB, or FGFR1 genes, resulting in the formation of fusion transcripts and aberrant tyrosine kinase activity. Eosinophilia is a characteristic finding but it is not always present. This group includes the myeloid and lymphoid neoplasms with $\mathrm{t}(8 ; 9)$ (p22;p24.1);PCM1-JAK2 as a provisional entity. 